\title{
Temperature increase of 21st century mitigation scenarios
}

\author{
D. P. Van Vuuren a,b, M. Meinshausenc, G.-K. Plattnerd,e, F. Joose,f, K. M. Strassmanne, S. J. Smithg, T. M. L. Wigleyh \\ S. C. B. Raperi, K. Riahij,k, F. de la Chesnaye', M. G. J. den Elzena , J. Fujinom, K. Jiang ${ }^{\text {n }}$, N. Nakicenovic ${ }^{\mathrm{m}}$, S. Paltsev ${ }^{\circ}$, \\ and J. M. Reilly
}

\begin{abstract}
${ }^{a}$ Global Sustainability and Climate, Netherlands Environmental Assessment Agency, P.O. Box 303, 3720 AH Bilthoven, The Netherlands; CPotsdam Institute for Climate Impact Research, P.O. Box 6012 03, D14412 Pottsdam, Germany; dEnvironmental Physics, Institute of Biogeochemistry and Pollutant Dynamics, ETH Zürich, Universitätstrasse 16, CH-8092 Zurich, Switzerland; ${ }^{e}$ Climate and Environmental Physics, Physics Institute, University of Bern, Sidlerstrasse 5, CH-3012 Bern, Switzerland; fOeschger Centre for Climate Change Research, University of Bern, CH-3012 Bern, Switzerland; gJoint Global Change Research Institute, Pacific Northwest National Laboratory, 8400 Baltimore Avenue, Suite 201, College Park, MD 20740-2496; hational Center for Atmospheric Research, P.O. Box 3000, Boulder, CO 80307-3000; 'Centre for Air Transport and the Environment, Manchester Metropolitan University, Manchester M15 6BH, United Kingdom; i International Institute for Applied Systems Analysis, A-2361 Laxenburg, Austria; kGraz University of Technology, Steyrergasse 30 A-8010 Graz, Austria; I'Global Climate Program, Electric Power Research Institute, 2000 L Street NW, Suite 805, Washington, DC 20036; mClimate Policy Assessment Section, Center for Global Environment Research, National Institute for Environmental Studies, 16-2 Onogawa, Tsukuba, Ibaraki 305-8506, Japan; ${ }^{n}$ Energy Research Institute, Beijing 100038, China; and 'Joint Program on the Science and Policy of Global Change, Massachusetts Institute of Technology, Cambridge, MA 02139
\end{abstract}

Edited by Stephen H. Schneider, Stanford University, Stanford, CA, and approved August 18, 2008 (received for review November 23, 2007)

\begin{abstract}
Estimates of 21st Century global-mean surface temperature increase have generally been based on scenarios that do not include climate policies. Newly developed multigas mitigation scenarios, based on a wide range of modeling approaches and socioeconomic assumptions, now allow the assessment of possible impacts of climate policies on projected warming ranges. This article assesses the atmospheric $\mathrm{CO}_{2}$ concentrations, radiative forcing, and temperature increase for these new scenarios using two reducedcomplexity climate models. These scenarios result in temperature increase of $0.5-4.4^{\circ} \mathrm{C}$ over 1990 levels or $0.3-3.4^{\circ} \mathrm{C}$ less than the no-policy cases. The range results from differences in the assumed stringency of climate policy and uncertainty in our understanding of the climate system. Notably, an average minimum warming of $\approx 1.4^{\circ} \mathrm{C}$ (with a full range of $0.5-2.8^{\circ} \mathrm{C}$ ) remains for even the most stringent stabilization scenarios analyzed here. This value is substantially above previously estimated committed warming based on climate system inertia alone. The results show that, although ambitious mitigation efforts can significantly reduce global warming, adaptation measures will be needed in addition to mitigation to reduce the impact of the residual warming.
\end{abstract}

climate | climate policy | stabilization | integrated assessment | scenario

A key indicator for climate change is the expected globalmean surface temperature increase. Future global temperature changes will be determined primarily by future emissions of greenhouse gases, ozone, and aerosol precursors and the response of the Earth system to those emissions. Any calculation of the potential range of future climate change requires consideration of both a plausible range of emissions scenarios and uncertainties in Earth system response, preferably by using results from multiple scenarios and models. The present analysis aims to map out the potential benefits of climate mitigation actions in terms of how much temperature increase can be avoided as a function of abatement effort. By including scenarios that are among the most stringent in the current literature, the analysis also provides quantitative insight into how much warming is likely to remain as a result of inertia within the energy system as well as the climate system. Such information is of critical importance in the climate policies that are currently being formulated.

The Fourth Assessment Report (AR4) of the Intergovernmental Panel on Climate Change (IPCC) (1) recently projected that by 2100 , global mean surface temperature would increase by $1.1-6.4^{\circ} \mathrm{C}$ over the 1990 level using the range of illustrative baseline (nonmitigation) emissions scenarios from six energyeconomic modeling teams that had been developed in the IPCC
Special Report on Emissions scenarios (SRES) (2) (the low end of the range results from the so-called B1 scenario; the upper range from the A1FI scenario). This uncertainty range originates both from the range in emissions scenarios and from the limited understanding of the climate system. Earlier, broadly consistent results for the same scenarios were reported in IPCC's Third Assessment Report (TAR) (3) $\left(1.4-5.8^{\circ} \mathrm{C}\right)$, in individual model studies (4), in probabilistic approaches $(5,6)$, and in multimodel intercomparison studies $(7,8)$. Others obtained similar estimates of baseline temperature ranges with independently developed nonmitigation scenarios (9). The SRES emissions scenarios, however, do not include explicit policies to mitigate greenhouse gas emissions, which would lower the extent of climate change experienced over the 21st Century. Some work (which is also reported in AR4) has been done on the so-called "climate change commitment," i.e., the warming that would occur if concentrations were kept at the year 2000 levels, with an estimated average value of $0.6^{\circ} \mathrm{C}$ over the course of the $21 \mathrm{st}$ Century $(10,11)$. However, this climate change commitment is only a hypothetical number because inertia in human systems will result in increasing concentrations in the near future, whereas, in the more distant future, both emissions and concentrations can fall. Scenarios based on credible and feasible mitigation strategies are arguably more relevant for policy making (12). Although there have been analyses based on multigas emissions pathways (e.g., refs. 13 and 14) and mitigation scenarios (15-21), a comprehensive assessment of climate impacts using a range of multigas mitigation scenarios from different models has not yet been made.

Progress in developing multigas mitigation scenarios now allows a comparison between climate consequences of such mitigation scenarios versus baseline scenarios. This comparison considers the major uncertainties: climate sensitivity, carbon

Author contributions: D.P.V.V., M.M., G.-K.P., F.J., K.M.S., S.J.S., T.M.L.W., S.C.B.R., K.R F.d.I.C., M.G.J.d.E., J.F., K.J., N.N., S.P., and J.M.R. designed research; D.P.V.V., M.M., G.-K.P., F.J., K.M.S., and S.J.S. performed research; D.P.V.V., M.M., G.-K.P., F.J., K.M.S., S.J.S., K.R., F.d.I.C., M.G.J.d.E., J.F., K.J., N.N., S.P., and J.M.R. analyzed data; and D.P.V.V., M.M., G.-K.P., F.J., K.M.S., S.J.S., T.M.L.W., S.C.B.R., K.R., F.d.I.C., M.G.J.d.E., J.F., K.J., N.N., S.P., and J.M.R. wrote the paper.

The authors declare no conflict of interest.

This article is a PNAS Direct Submission.

Freely available online through the PNAS open access option.

bTo whom correspondence should be addressed. E-mail: detlef.vanvuuren@pbl.nl.

This article contains supporting information online at www.pnas.org/cgi/content/full/ 0711129105/DCSupplemental.

() 2008 by The National Academy of Sciences of the USA 

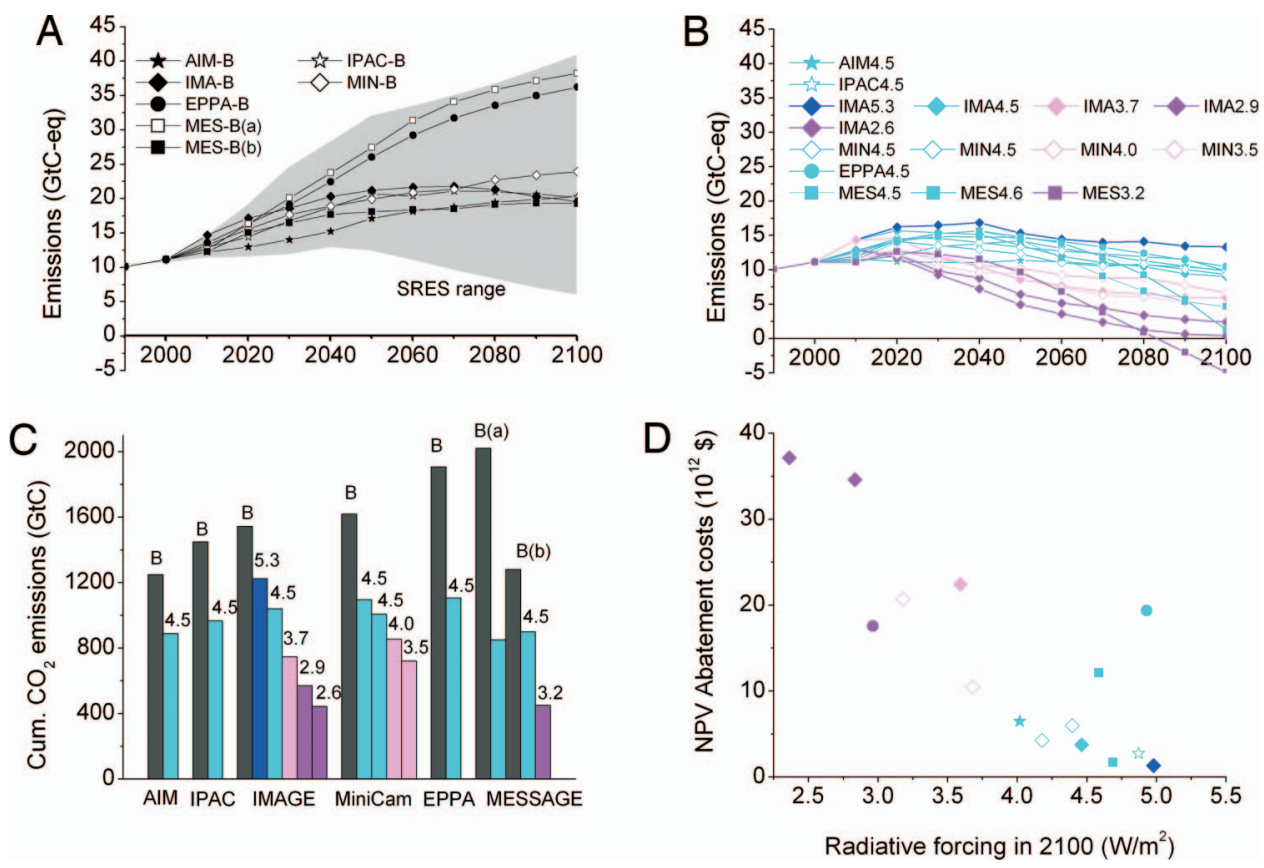

Fig. 1. Emissions of equivalent $\mathrm{CO}_{2}$ under the baseline scenarios $(A)$ and mitigation scenarios $(B)$, comparison of cumulative $\mathrm{CO}_{2}$ emissions $(C)$, and the net present value (NPV) of abatement costs (D). Emissions in $A$ and $B$ are expressed in $\mathrm{CO}_{2}$-equivalent emissions for illustrative purposes. The numbers used to identify the scenarios refer to actual forcing target used within the models. $D$ shows the approximate NPV of abatement costs (see $S / T$ Text) as a function of year-2100 radiative forcing as calculated by MAGICC. The colors indicate the different grouping (black, baseline; light blue, $4.5 \mathrm{~W} / \mathrm{m}^{2}$ stabilization scenarios from EMF-21; dark blue, scenarios with higher stabilization targets than EMF-21; pink, scenarios with targets in between 3.5 and $4 \mathrm{~W} / \mathrm{m}^{2}$; and purple, scenarios with targets $\left.<3.5 \mathrm{~W} / \mathrm{m}^{2}\right)$.

cycle processes, socioeconomic modeling approach, climate modeling approach, different baseline assumptions, and climate policy uncertainty (different stabilization levels).

For this article, a set of baseline and associated mitigation scenarios was compiled from a group of Integrated Assessment Models (IAM) with results for the most relevant greenhouse gases and air pollutants (although these model also calculate greenhouse gas concentration and climate change, here, we use only their emission outputs). These models are AIM, EPPA, IMAGE, IPAC, MESSAGE and MiniCAM (22-30). The IAMs include all major greenhouse gases $\left(\mathrm{CO}_{2}, \mathrm{CH}_{4}, \mathrm{~N}_{2} \mathrm{O}\right.$, and halocarbons) and consistent representations of air pollutants, i.e., aerosols $\left(\mathrm{SO}_{2}\right)$ and tropospheric ozone precursors $(\mathrm{CO}$, $\mathrm{NO}_{\mathrm{x}}, \mathrm{VOCs}$ ). The mitigation scenarios focus on stabilizing radiative forcing (as a useful integrating metric across agents). Most of the scenarios were developed for the EMF-21 model comparison $(31,32)$. Together, they represent a wide range of different approaches in modeling the socioeconomic system and capture major uncertainties associated with future emissions.

Here, the radiative forcing and climate implications of the emissions projections were simulated by using two climate models [see supporting information (SI) Text]: a relatively simple climate model (MAGICC) (5) and an earth system model of intermediate complexity (Bern2.5CC) $(33,34)$. Both models simulate atmospheric gas cycles including the effect of air pollutant gases, radiative forcing, and temperature change. In both cases, global emissions were used as model input. MAGICC couples global carbon and gas cycle models with a onedimensional upwelling diffusion model of ocean heat transport, here tuned to emulate global mean climate responses of 19 coupled atmospheric-ocean models. The Bern2.5CC model combines a zonally averaged dynamic ocean model with models for the atmosphere, thermodynamic sea ice, marine carbon cycle, and dynamic vegetation. Both models have been used extensively in IPCC reports, and the combination is used here to get some representation of model differences as they contribute to uncertainty. For that reason, they are used here in their standard IPCC model setup (see SI Text). Results are presented as ranges with climate sensitivity and carbon-cycle parameters varied over plausible ranges. Throughout this article, temperature increase is reported in comparison with 1990 levels, defined as the average over 1980-2000 (see SI Text for additional metrics and/or other reference periods sometimes used in the literature).

\section{Emissions Scenarios}

In the baseline (no climate policy) scenarios, the range of increase in greenhouse gas emissions by 2100 is from $\approx 70 \%$ to almost $250 \%$ compared with 2000 in the absence of climate policy [Fig. 1; emissions are reported in equivalents by using global warming potentials (35) for reporting purposes only]. In all baseline scenarios, emissions growth slows down in the second half of the century because of a combination of stabilizing global population levels and continued technological change. The scenario range used here is reasonably representative of values in the current literature (31) and broadly consistent with the SRES-range. The current set of baseline scenarios lacks cases with substantial declines in emissions over the last part of the 21st Century, which increases the lower end of temperature range for baseline scenarios somewhat compared with AR4, as indicated further below.

The mitigation scenarios necessarily follow a very different pattern, with a peak in global emissions between 2020 and 2040 at a maximum value of $50 \%$ above current emissions levels. The mitigation scenarios can be classified into categories according to their radiative forcing target. A large group of the scenarios (8 of 15) aim for stabilization (ca. 2150) at $4.5 \mathrm{~W} / \mathrm{m}^{2}$ compared with preindustrial, which was the target of the EMF-21 exercise (hereafter referred to as " $4.5 \mathrm{~W} / \mathrm{m}^{2}$ " target). Note that the results presented here do not necessarily stabilize at $4.5 \mathrm{~W} / \mathrm{m}^{2}$ when simulated through the climate models used here because 
A
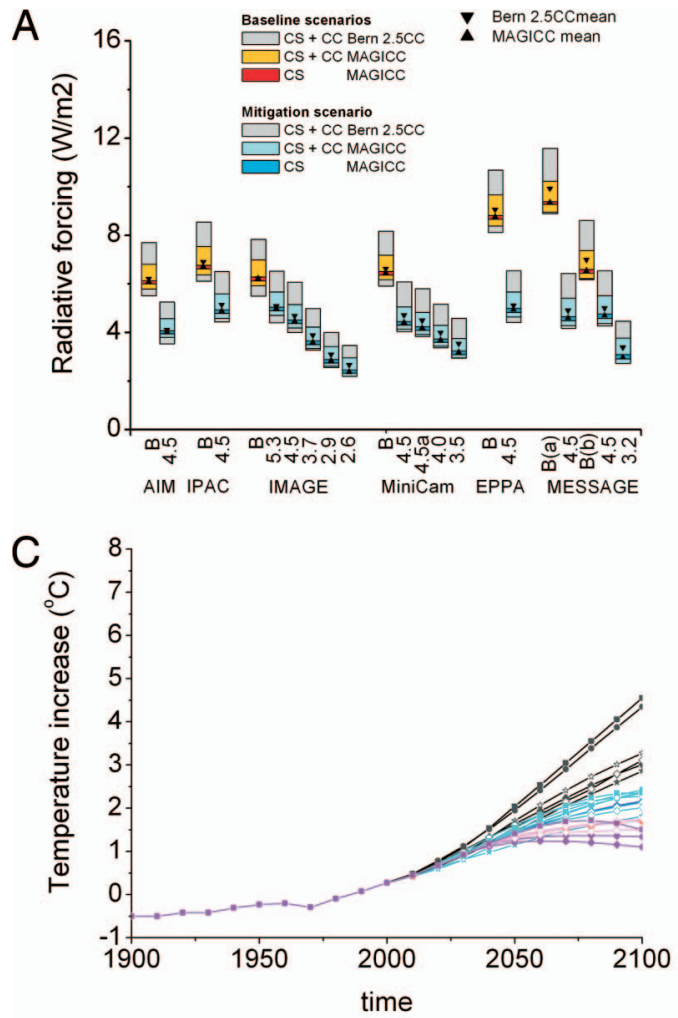

B
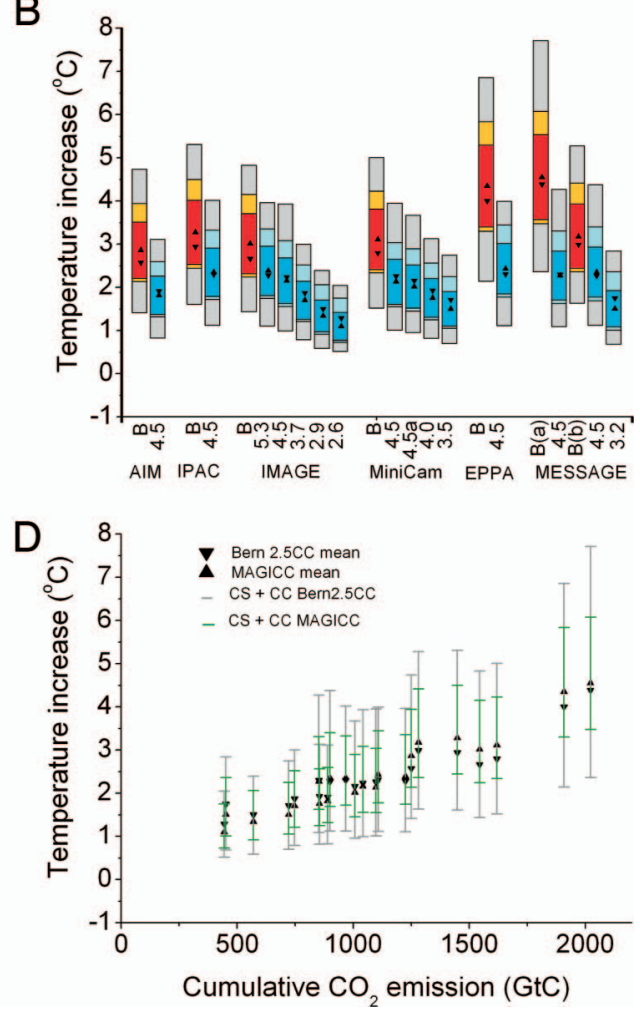

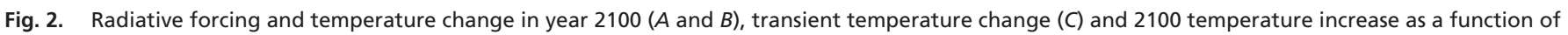

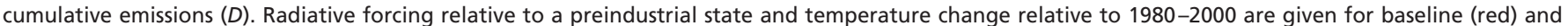

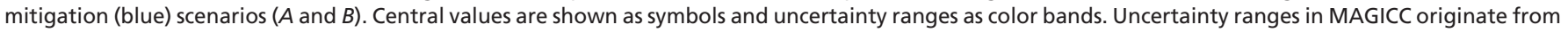

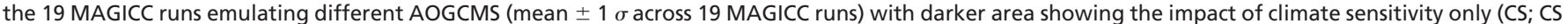

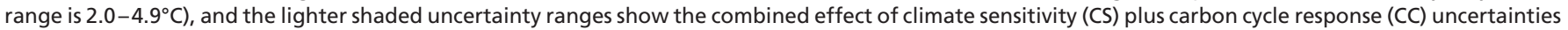

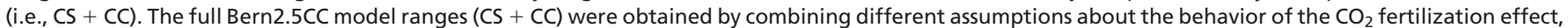

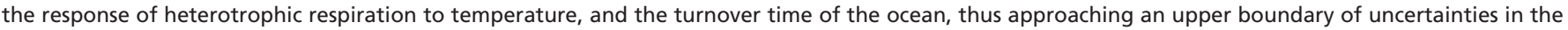

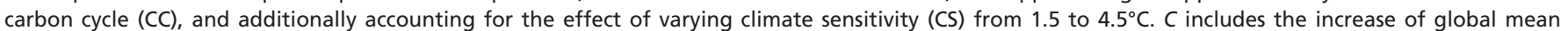

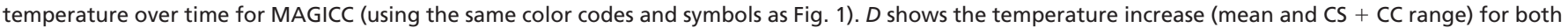
climate models as a function of cumulative $\mathrm{CO}_{2}$ emissions from 2000 to 2100 .

they may represent the carbon cycle and the fate of gases somewhat differently than did the original modeler. This group of scenarios shows cumulative $\mathrm{CO}_{2}$ emissions of 850 -to 1,000 Gigaton Carbon (GtC) (Fig. 1C), on average reduced by $40 \%$ compared with the baseline. One mitigation scenario has higher $(1,100 \mathrm{GtC})$ and several have considerably lower cumulative emissions (400-850 GtC). The lowest scenarios (IMAGE29, IMAGE26, MESSAGE32-purple in Figs. 1 and 2C) have forcing targets $<3.5 \mathrm{~W} / \mathrm{m}^{2}$ (hereafter referred to as "lowest scenarios").

The mitigation scenarios are developed in each of the integrated assessment model by selecting a cost-effective set of emission reduction measures. In general, most reductions are obtained by reducing energy-related $\mathrm{CO}_{2}$ emissions (70-90\% of reductions across the scenarios), followed by non- $\mathrm{CO}_{2}$ gases (15-30\%) and $\mathrm{CO}_{2}$ from land-use (relatively small contribution; both positive and negative as side effects of other reductions measures). Energy-related $\mathrm{CO}_{2}$ emissions are generally reduced by increases in energy efficiency and application of low/zero carbon energy technologies. In terms of timing, models aim to avoid drastic emission reductions that require (costly) premature reduction of capital; in other words, emission reductions are bounded by the inertia of capital replacement in the energy system. The emission reductions in 2050 vary considerably as a function of the stabilization target. For the $4.5 \mathrm{~W} / \mathrm{m}^{2}$ target, year-2050 emissions are 2-30\% lower than the year-2000 emissions, but for the category of lowest scenarios, emissions are
$20-60 \%$ lower than in year 2000. The category of lowest scenarios tend to push the limits in terms of rate and direction of technological and lifestyle changes. For example, they include the use of bioenergy in combination with carbon-capture and storage, which provides the possibility of net negative emissions from electricity production (36). These scenarios are among the lowest emissions scenarios currently found in the literature (17).

Air pollutant emissions are always lower in the mitigation scenarios than in the baseline scenarios (e.g., 19-88 Teragram Sulphur (Tg S)/yr for the baseline scenarios versus 4-54 Tg S/yr for the mitigation scenarios in 2100). $\mathrm{CO}_{2}$ emissions reduction and $\mathrm{SO}_{2}$ emissions reduction are tightly coupled $\left(r^{2}=0.64\right.$; slope $=1.08$ ); a correlation is also found for $\mathrm{NO}_{\mathrm{x}}, \mathrm{VOCs}$ and $\mathrm{CO}$ (SI Text). These correlations result from the changes induced by climate policies in the energy system and are important because these gases also influence radiative forcing via aerosol and ozone formation. In the short term, the coupling between $\mathrm{SO}_{2}$ and $\mathrm{CO}_{2}$ emission reduction is crucial because part of the reduced warming resulting from lower $\mathrm{CO}_{2}$ emissions is offset by additional warming due to reduced $\mathrm{SO}_{2}$ emissions (37).

The change in abatement cost as a function of the policy target, here represented by radiative forcing in 2100 , is shown in Fig. $1 D$ (see SI Text). As a generic costs measure, the net present value (NPV) of abatement costs is used. The general result is a strong correlation between more ambitious targets and increasing costs. The costs for any particular target varies substantially depending on assumptions for technological options considered, 
the rate of technological change, substitution between production factors (e.g., capital and energy), recycling of tax revenues, and baseline emissions (38). For the $4.5 \mathrm{~W} / \mathrm{m}^{2}$ target, the net present value of abatement costs from 2000 to 2100 range from 2 to 19 trillion 2000-US\$ across the models. The highest cost levels (for the most stringent targets) are equivalent to about 2-3\% of NPV of GDP (see also Discussion and Conclusions).

\section{Outcomes of the Climate Models}

Radiative forcing (Fig. 2A) shows the integrated effect of the complete suite of greenhouse gases, aerosols, and precursors and stratospheric and tropospheric ozone. Baseline case forcing in 2100 for central parameters ranges from 6 to $10 \mathrm{~W} / \mathrm{m}^{2}$ compared with preindustrial over the range of emissions scenarios. Forcing in mitigation cases is stabilized or declining by 2100 , with values reduced to $2.4-5.1 \mathrm{~W} / \mathrm{m}^{2}$. Both the MAGICC and Bern2.5CC models show similar results for central climate and carbon cycle parameters. The uncertainty ranges, however, are not directly comparable. For Bern2.5CC, the range results from plausible assumptions on upper and lower limits for carbon sequestration by land and ocean (34). For MAGICC, the range is the \pm 1 standard deviation range across a set of 19 MAGICC runs (see SI Text).

The carbon dioxide concentrations for the baseline cases range from $650-950 \mathrm{ppm}$ in 2100 by using central model parameters (for both climate models). Carbon dioxide concentrations in the mitigation scenarios range from 380 to $620 \mathrm{ppm}$ in 2100 . The subset of $4.5 \mathrm{~W} / \mathrm{m}^{2}$-target scenarios yields a $\mathrm{CO}_{2}$ concentration range of 500-590 ppm for central carbon-cycle/ climate parameters.

Projected temperature changes by year 2100 (relative to 1990) are $2.6-4.6^{\circ} \mathrm{C}$ (Fig. $2 B$ ) for the baseline scenarios and central (best-estimate) model parameters. Uncertainties in the carbon cycle and climate sensitivity more than double the ranges associated with emissions to $2.1-6.1^{\circ} \mathrm{C}$ in MAGICC and results in an even wider range of possible outcomes in the Bern2.5CC model of $1.4-7.7^{\circ} \mathrm{C}$. The range of MAGICC outcomes is on the low end of the range somewhat higher than the numbers reported in TAR and AR4 $\left(1.1^{\circ} \mathrm{C}\right)$ as a result of the fact that here no scenarios have been considered that significantly reduce emissions without climate policy $(1,3)$. Apart from this, the numbers are broadly consistent.

For the mitigation scenarios, the projected temperature changes by 2100 are $1.1-2.4^{\circ} \mathrm{C}$ by using central model parameters. The mitigation scenarios bring down the overall range of temperature change substantially relative to the baseline range with the largest impact on the high end of the range, which is lowered by $>3^{\circ} \mathrm{C}$. The greatest difference compared with the baseline is seen during the second part of the century, when the rate of temperature change slows considerably in all mitigation scenarios in contrast to the baseline scenarios. By the end of century, the rate of temperature change under the mitigation scenarios is considerably below the rate of the baseline scenarios (which still show strongly increasing temperature). In fact, under default assumptions in climate parameters in several mitigation scenarios, surface air temperature has more or less stabilized by year 2100. In other words, the policy scenarios have even a greater impact on the additional warming beyond 2100 than the differences reported for that particular year. For the $4.5 \mathrm{~W} / \mathrm{m}^{2}$ target, climate model simulations result in a 2100 temperature increase of $0.8-4.4^{\circ} \mathrm{C}$ (full Bern $2.5 \mathrm{CC}$ range).

The temperature increase is $1.1-1.7^{\circ} \mathrm{C}$ for the central model parameter settings for the lowest emissions scenarios, with a full range of $0.5-2.8^{\circ} \mathrm{C}$ in the Bern2.5CC model (Fig. 2). Thus, even under these low scenarios, global mean temperature increase could exceed $2^{\circ} \mathrm{C}$ compared with 1990 depending on climate or carbon-cycle parameters. Assuming that these scenarios represent a lower bound on feasible emissions reductions, these results represent an estimate of the "minimum warming" that considers inertia of both the climate system and socioeconomic systems. The average warming of these scenarios is $1.4^{\circ} \mathrm{C}$, of which $\approx 0.6^{\circ} \mathrm{C}$ is due to the climate system inertia alone (6). The socioeconomic and technological inertias thus account for $\approx 0.8^{\circ} \mathrm{C}$ additional warming by 2100 relative to 1990 .

The temperature change in the different scenarios is closely related to the 1990-2100 cumulative carbon emissions (industrial and land-use change), with deviations varying according to other emissions (air pollutants, non- $\mathrm{CO}_{2}$ greenhouse gases) and emissions pathway. The correlation between cumulative industrial $\mathrm{CO}_{2}$ emissions and temperature change in 2100 yields a standard deviation of $0.2^{\circ} \mathrm{C}$ (SI Text). Deviations from a perfect correlation are due mainly to the effects of non- $\mathrm{CO}_{2}$ greenhouse gases.

\section{Discussion and Conclusions}

We have examined a large set of projections for 21st Century emissions of a suite of greenhouse and other air pollutant gases. The emissions scenarios provide an indication of the potential effects of mitigation policies. In interpreting these results, however, it should be noted that most of the emissions models used are idealized in many ways. New technologies and policies are assumed to be globally applicable and are often introduced over relatively short periods of time. Especially in the lowest scenarios, it is assumed that some form of global climate policy can be implemented shortly after 2010, as a result of which global emissions can peak $\mathrm{ca}$. 2020. On the other hand, some future mitigation options might not have been considered to the full extent. The scenarios here do not generally deal with the question of political feasibility and assume, for example, that mitigation policies are implemented globally and in all sectors of the economy.

Consider first the $4.5 \mathrm{~W} / \mathrm{m}^{2}$ scenarios, which represent a stabilization target of the magnitude often considered by energyeconomic analyses. Global emissions in these scenarios begin to diverge from baseline values $c a$. 2020-2030, with emissions dropping to approximately present levels by 2100 . Achieving any of these emissions pathways is likely to be challenging compared with past and present mitigation efforts, although views on the magnitude of this challenge differ widely. Temperature starts to diverge from the baseline projections later than emissions. This delay emphasizes the importance of early decisions to meet specific mitigation targets. By the end of the century, the climate consequences of the $4.5 \mathrm{~W} / \mathrm{m}^{2}$ target scenarios result in temperature changes of $0.8-4.4^{\circ} \mathrm{C}$ relative to 1990 average instead of a warming of $1.4-7.7^{\circ} \mathrm{C}$ for the baseline projections. Central model parameter settings in 2100 result in $\approx 2.1^{\circ} \mathrm{C}$ for the $4.5 \mathrm{~W} / \mathrm{m}^{2}$ target instead of $2.4-4.6^{\circ} \mathrm{C}$ for the baseline projections. It should be noted that the mitigation scenarios also have a lower warming commitment beyond 2100 than the baseline scenarios.

The lowest scenarios result in a warming of $0.5-2.8^{\circ} \mathrm{C}$ (average $1.4^{\circ} \mathrm{C}$ ). These scenarios provide a guide to the range of global-mean warming that may occur, assuming ambitious climate policy. The value could be interpreted as a more realistic minimum warming based on technological and economic inertia (although given the nature of uncertainty in emission modeling, the lower bound given here is not a formal one; it simply reflects the assumptions of what is possible based on model assumptions). Its value is substantially above previously estimated committed warming due to climate system inertia only $\left[0.2-1.0^{\circ} \mathrm{C} ;(10,11)\right]$. It should be noted that these scenarios depart from the corresponding no-climate-policy baseline by $2015-2020$. Furthermore, they incorporate the widespread development and deployment of existing carbonneutral technologies in coming decades and, subsequently, of new carbon-neutral technologies. Although the integrated assessment/energy economics model runs indicate that these 
scenarios may be technically feasible, they clearly require sociopolitical and technical conditions very different from those now existing.

Under the lowest scenarios analyzed here, therefore, meeting a target of $2^{\circ} \mathrm{C}$ temperature change relative to preindustrial conditions (i.e., $1.5^{\circ} \mathrm{C}$ relative to $1980-2000$ ) is possible, but is not at all guaranteed. Obviously, the chances of meeting the target decrease substantially for less-stringent stabilization targets. Given the large uncertainty ranges resulting from our

1. Solomon S, et al. (2007) Climate Change 2007: The Physical Science Basis. Contribution of Working Group I to the Fourth Assessment (Cambridge Univ Press, Cambridge, UK).

2. Nakicenovic N, Swart R (2000) Special Report on Emissions Scenarios (SRES) (Cambridge Univ Press, Cambridge, UK).

3. Cubash U, Meehl GA (2001) in Climate Change 2001: The Scientific Basis, eds Houghton JT, et al. (Cambridge Univ Press, Cambridge, UK).

4. Joos F, et al. (2001) Global warming feedbacks on terrestrial carbon uptake under the Intergovernmental Panel on Climate Change (IPCC) emission scenarios. Global Biogeochem Cycles 15:891-907.

5. Wigley TML, Raper SCB (2001) Interpretation of high projections for global-mean warming. Science 293:451-454.

6. Knutti R, Stocker TF, Joos F, Plattner GK (2002) Constraints on radiative forcing and future climate change from observations and climate model ensembles. Nature 416:719-723.

7. Friedlingstein $P$, et al. (2006) Climate-carbon cycle feedback analysis, results from the C4MIP model intercomparison. J Clim 19:3337-3353.

8. Meehl GA, Covey C, McAvaney B, Latif M, Stouffer RJ (2005) Overview of the coupled model intercomparison project. Bull Am Meteorol Soc 86:89-93.

9. Webster MD, et al. (2002) Uncertainty in emissions projections for climate models Atmos Environ 36:3659-3670.

10. Wigley TML (2005) The climate change commitment. Science 307:1766-1769.

11. Meehl GA, et al. (2005) How much more global warming and sea level rise? Science 307:1769-1772.

12. Hare $B$, Meinshausen $M$ (2006) How much warming are we committed to and how much can be avoided? Clim Change 75:111-149.

13. Meinshausen M, et al. (2006) Multi-gas emission pathways to meet climate targets Clim Change 75:151-194.

14. O'Neill BC, Oppenheimer M (2004) Climate change impacts are sensitive to the concentration stabilization path. Proc Natl Acad Sci USA 101:16411-16416.

15. Manne AS, Richels RG (2001) An alternative approach to establishing trade-offs among greenhouse gasses. Nature 5:675-677.

16. Webster MD, et al. (2003) Uncertainty analysis of climate change and policy response. Clim Change 61:295-320.

17. Fisher B, et al. (2007) in Climate Change 2007-Mitigation, eds Metz B, Davidson O, Bosch P, Dave R, Meyer L (Cambridge Univ Press, Cambridge, UK).

18. Keppo I, O'Neill BC, Riahia K (2007) Probabilistic temperature change projections and energy system implications of greenhouse gas emission scenarios. Technol Forecast Soc Change 74:936-961.

19. Mastandrea MD, Schneider SH (2004) Probabilistic integrated assessment of dangerous climate change. Science 304:571-574.

20. Wigley TML, et al. (2008) Uncertainties in climate stabilization. Clim Change, in press.

21. Den Elzen MGJ, Van Vuuren DP (2007) Peaking profiles for achieving long-term temperature targets with more likelihood at lower costs. Proc Natl Acad Sci USA 104:17931-17936. limited understanding/knowledge of climate sensitivity and carbon cycle processes, the results reconfirm the need to formulate targets in probabilistic terms $(5,39,40)$. Our results show that even the lowest scenarios available in literature, based on optimistic assumptions with respect to international cooperation in climate policy, lead to considerable increases in global mean temperature. These results show that adaptation measures will be needed in addition to mitigation to reduce the impact of the residual warming.

22. Reilly J, Sarofim M, Paltsev S, Prinn R (2006) The role of non- $\mathrm{CO}_{2}$ greenhouse gases in climate policy: Analysis using the MIT IGSM. Energy Journal Special Issue 3:503-520.

23. van Vuuren DP, Eickhout B, Lucas P, den Elzen MGJ (2006) Long-term multi-gas scenarios to stabilise radiative forcing-Exploring costs and benefits within an integrated assessment framework. Energy Journal Special Issue 3:201-234.

24. Clarke LE, et al. (2007) Scenarios of Greenhouse Gas Emissions and Atmospheric Concentrations. Sub-report 2.1a of Synthesis and Assessment Product 2.1. (Climate Change Science Program and the Subcommittee on Global Change Research, Washington DC).

25. Jiang K, Hu X, Songli Z (2006) MultiGas mitigation analysis by IPAC Energy Journal Special Issue 3:425-440.

26. Rao S, Riahi $\mathrm{K}$ (2006) The role of non- $\mathrm{CO}_{2}$ greenhouse gases in climate change mitigation: Long-term scenarios for the 21st Century. Energy Journal Special Issue 3:177-200.

27. Fujino J, Nair R, Kainuma M, Masui T, Matsuoka Y (2006) Multigas mitigation analysis on stabilization scenarios using Aim Global model Energy Journal Special Issue 3:343-354.

28. Smith SJ, Wigley TML (2006) MultiGas forcing stabilization with minicam Energy Journal Special Issue 3:373-392.

29. van Vuuren DP, et al. (2007) Stabilizing greenhouse gas concentrations at low levels: An assessment of reduction strategies and costs. Clim Change 81:119-159.

30. Riahi K, Gruebler A, Nakicenovic N (2007) Scenarios of long-term socio-economic and environmental development under climate stabilization. Forecast Soc Change 74:887 935.

31. van Vuuren DP, Weyant J, de la Chesnaye F (2006) Multigas scenarios to stabilise radiative forcing. Energy Econ 28:102-120.

32. Weyant JP, de la Chesnaye FC, Blanford GJ (2007) Overview of EMF21: Multigas mitigation and climate policy. Energy Journal Special Issue 3:1-32.

33. Plattner G-K, Joos F, Stocker TF, Marchal O (2001) Feedback mechanisms and sensitiv ities of ocean carbon uptake under global warming. Tellus 53B:564-592.

34. Plattner G-K, et al.(2008) Long-term climate commitments projected with climateCarbon cycle models. J Clim 21:2721-2751.

35. Ramaswamy V, et al. (2001) in Climate Change 2001: The Scientific Basis, eds Houghton JT, et al. (Cambridge Univ Press, Cambridge, UK).

36. Azar C, Lindgren K, Larson E, Möllersten K (2006) Carbon capture and storage from fossil fuels and biomass-Costs and potential role in stabilizing the atmosphere. Clim Change 74:47-79

37. Wigley TML (1991) Could reducing fossil-fuel emissions cause global warming. Nature 349:503-506.

38. Weyant JP (2000) An Introduction to the Economics of Climate Change Policy (Pew Center on Global Climate Change, Washington DC)

39. Knutti R, Joos F, Mueller SA, Plattner GK, Stocker TF (2005) Probabilistic climate change projections for stabilization profiles. Geophys Res Lett 32:L20707.

40. Meinshausen M (2006) in Avoiding Dangerous Climate Change, eds Schellnhuber HJ, Cramer W, Nakicenovic N, Wigley T, Yohe G (Cambridge Univ Press, Cambridge, UK). 